\title{
DEDIFFERENTIATED LIPOSARCOMA OF FOOT - A CASE REPORT
}

\author{
R. G. Naniwadekar ${ }^{1}$, Roshan Chiranjeev², Neha Suhas Sawant ${ }^{3}$
}

1 Professor, Department of General Surgery, Krishna Institute of Medical Sciences.

${ }^{2}$ Resident, Department of General Surgery, Krishna Institute of Medical Sciences.

${ }^{3}$ Resident, Department of General Surgery, Krishna Institute of Medical Sciences.

\section{ABSTRACT}

Liposarcoma is categorised as a second most common soft tissue sarcoma with a peak incidence between the fourth and sixth decade of life with a slight preponderance towards male gender. Dedifferentiated liposarcoma is a rare sarcoma accounting for only $2 \%$ of all soft tissue sarcomas. It is defined as the morphological progression of well-differentiated liposarcoma to a non-adipocytic sarcoma. Here, we present a case of primary dedifferentiated liposarcoma arising in the foot of an 80-year-old female who had presented with swelling over dorsum of foot since 1 year. Patient underwent wide surgical excision for the same followed by postoperative radiotherapy treatment. Liposarcoma is most common in the lower extremities; however, its presentation is rare over foot.

\section{KEYWORDS}

Soft Tissue Sarcoma, Dedifferentiated Liposarcoma, Foot.

HOW TO CITE THIS ARTICLE: Naniwadekar RG, Chiranjeev R, Sawant NS. Dedifferentiated liposarcoma of foot - A case report. J. Evolution Med. Dent. Sci. 2016;5(87):6526-6528, DOI: 10.14260/Jemds/2016/1476

\begin{abstract}
BACKGROUND
Liposarcoma is the second most common soft tissue sarcoma in adults. This tumour originates from multipotential primitive mesenchymal cells rather than mature adipose tissue. The peak age incidence is between 4th and 6th decade of life with slight preponderance towards male gender. They often present as relatively slow growing asymptomatic masses generally located in thigh, gluteal region, retroperitoneum, leg, inguinal, paratesticular and shoulder area, chest wall, breast, mediastinum, small intestine, omentum and mesentery may be involved. Liposarcoma can be divided according to clinicopathological and cytogenetic characteristics into three distinct subtypes - well-differentiated, myxoid/round cells and pleomorphic liposarcoma. We describe an unusual case of rapidly growing foot dedifferentiated liposarcoma of foot which is rare.
\end{abstract}

\section{CASE PRESENTATION}

An 80-year-old female patient presented in the outpatient department of Krishna Institute of Medical Sciences with chief complaints of swelling on the dorsum of right foot since 1 year which was insidious in onset and has gradually increased in size from the size of a lemon to present size with no aggravating or relieving factors. The swelling is associated with gradually increasing throbbing nature of intermittent pain which would aggravate on walking. Two years before she had a history of soft tissue injury at the same location, but without any complication or sequelae. There was no history of fever, colour change, bony pain, weight loss and claudication. The comorbidities associated with the patient are recently diagnosed diabetes mellitus and hypertension.

Financial or Other, Competing Interest: None.

Submission 23-09-2016, Peer Review 14-10-2016,

Acceptance 23-10-2016, Published 29-10-2016.

Corresponding Author:

Dr. Roshan Chiranjeev,

Room No. 46, IHR Residents Hostel,

Krishna Institute of Medical Sciences,

Karad-415110, Dist-Satara,

Maharashtra.

E-mail: roshanchiranjeev@yahoo.co.in

DOI: $10.14260 /$ jemds $/ 2016 / 1476$
Her family history revealed no lipomatous disorders. Patient is a chronic tobacco chewer since 40 years. The menstrual and obstetric history was not significant. On examination, patient was vitally stable with moderate pallor. On physical examination, a single soft nontender mass was present over dorsum of right foot, $15 \times 12 \times 4 \mathrm{~cm}$, poorly defined from surrounding tissue attached to underlying structures and skin was detected with no discolouration, raised temperature and pulsations. The mass was negative for fluctuation test and transillumination test. No bruit was heard. The blood investigation revealed leucocytosis with raised blood sugar levels.

The plain x-ray of right foot shows evidence of large soft tissue swelling over the foot with osteoarthritis of 1 st metatarsophalangeal joint and diffuse osteoporosis. Ultrasonography of the mass demonstrates a large heterogenous, low reflective soft tissue solid mass within the dorsal subcutaneous tissue of right foot with large septations. It is a non-compressible, non-calcified lesion with multiple areas of cystic degeneration and necrosis. Significant peripheral and septal hypervascularity noted encasing most of digital branches. However, there is no involvement of flexor tendons or muscle plane. Computed tomography is suggestive of a large well-defined, round-to-oval, fibrocystic multiloculated lesion over dorsum of foot involving subcutaneous plane with multiple septations within it measuring $11.5 \times 7.8 \times 5.0 \mathrm{~cm}$. The lesion shows fibrous component which is heterogeneously hyperintense on T1FS, heterointense on T2W1/PDFS and cystic component in T2W1, largest measuring $4.1 \times 3.6 \times 2.9 \mathrm{~cm}$, s/o fibrolipomatous lesion. Fine needle aspiration cytology of the mass reveals myxoid liposarcoma over myxoid chondrosarcoma and atypical lipomatous tumour.

Patient underwent wide excision with delayed wound healing in an otherwise uneventful postoperative period. The histopathology of the lesion was malignant adipose tissue tumour suggestive of dedifferentiated liposarcoma and the overlying skin being free from tumour. 


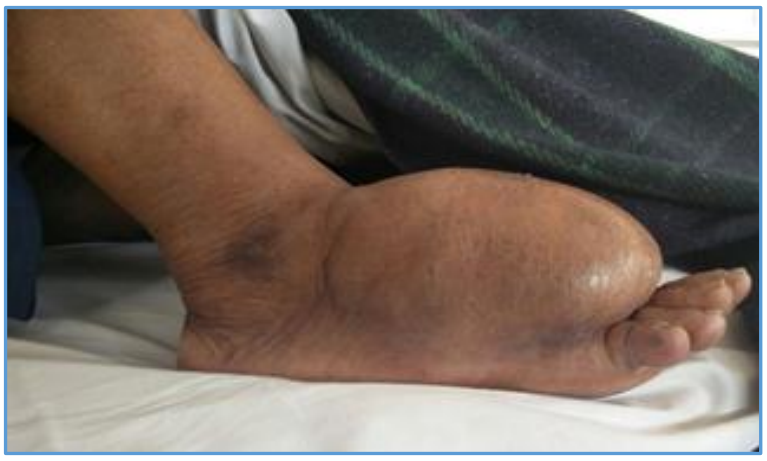

Figure 1. Pre-operative Lateral View

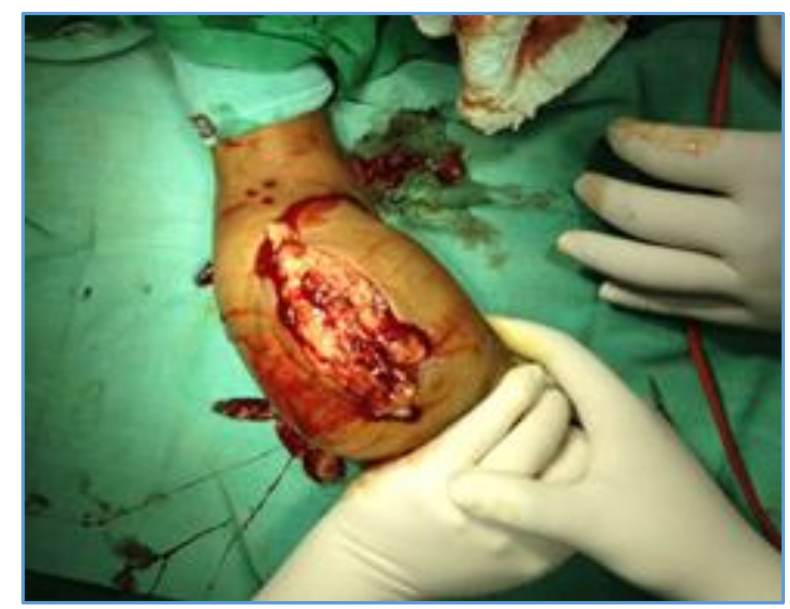

Figure 2. Intra-operative

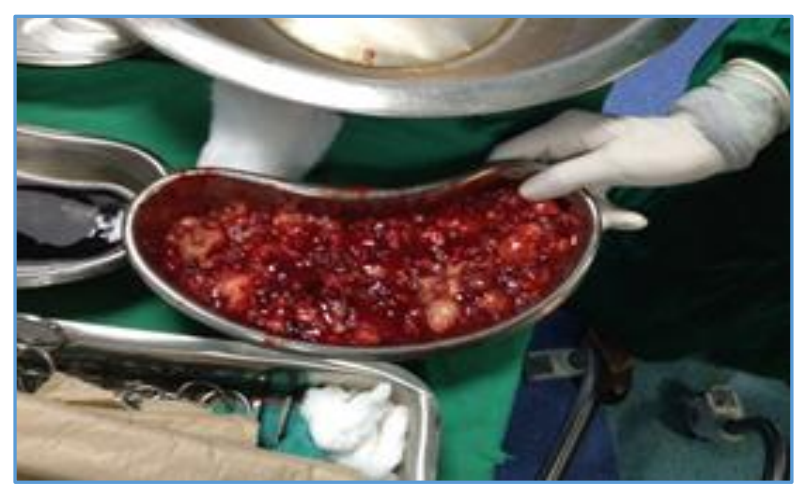

Figure 3. Specimen

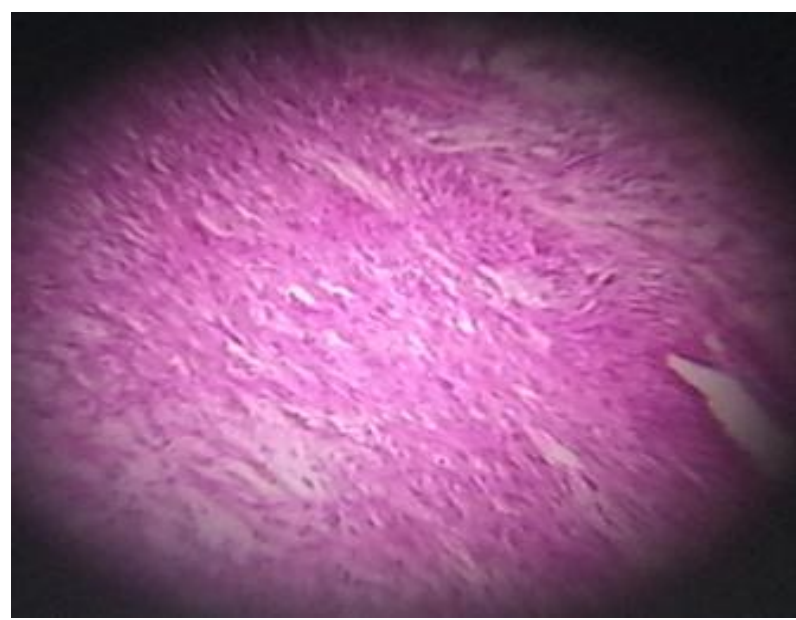

Figure 4. Histopathology Image 1

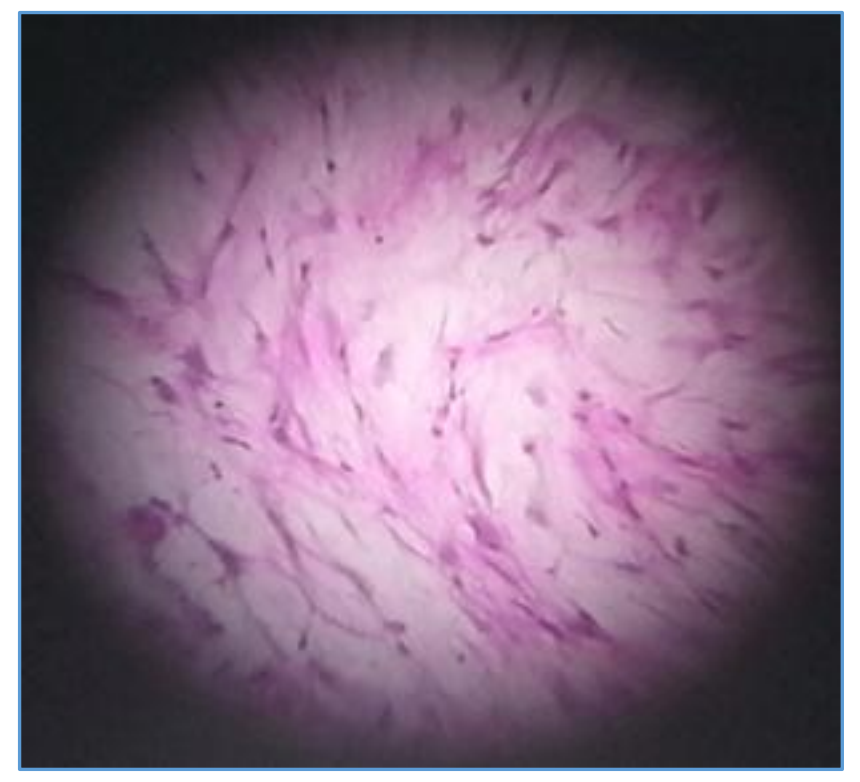

Figure 5. Histopathology Microscopic Image 2

\section{DISCUSSION}

As far as adipocytic tumours are concerned, they can be broadly categorised as malignant or benign. Out of these, malignant adipocytic tumours constitute roughly 20\%.[1] Dedifferentiated liposarcoma is a relatively new tumour introduced by Evans in 1979.[2] A very small number of cases only have showed low grade areas of dedifferentiation. [2],[3]\&[4] Dedifferentiated liposarcoma is a tumour which has a highly cellular non-lipogenic component along with a welldifferentiated liposarcoma. It is most common in males over 50 years of age and occurs in the retroperitoneum,[3] followed by deep soft tissues of thighs, neck and head region, trunk, mediastinum and the spermatic cord.[5],[1] Approximately, $90 \%$ of dedifferentiated liposarcoma occur de novo and the other $10 \%$ is mainly due to the recurrence of a primary welldifferentiated liposarcoma. Dedifferentiated liposarcoma presents as large swelling with soft to firm consistency, large size and with irregular margins. On the inside, it presents as a large yellowish multinodular mass often as large as $20 \mathrm{~cm}$ and is well demarcated from the dedifferentiated component which appears as greyish-white firm-to-hard nodules. Transition between two areas can be gradual or abrupt as is, in our case. Very few cases in literature have quoted dedifferentiated liposarcoma of foot in an elderly female.

\section{CONCLUSION}

This paper represents a case of dedifferentiated liposarcoma of foot in an 80-year-old female patient. This case has been chosen for discussion here due to low occurrence of dedifferentiated liposarcoma of foot in an elderly female patient.

\section{REFERENCES}

1. Weis SW, Godblum JR. Enzinger and Weiss's soft tissue tumors. $5^{\text {th }}$ ed. St. Louis: Mosby, Elsevier 2008.

2. Henricks WH, Chu YC, Goldblum JR, et al. Dedifferentiated liposarcoma: a clinicopathological analysis of 155 cases with a proposal for an expanded definition of dedifferentiation. Am J Surg Pathol 1997;21(3):271-81. 
3. Elgar F, Goldblum JR. Well-differentiated liposarcoma of the retroperitoneum: a clinicopathologic analysis of 20 cases, with particular attention to the extent of low grade dedifferentiation. Mod Pathol 1997;10(2):113-20.

4. Huang HY, Brennan MF, Singer S, et al. Distant metastasis in retroperitoneal dedifferentiated liposarcoma is rare and rapidly fatal: a clinicopathological study with emphasis on the low grade myxofibrosarcoma-like pattern as an early sign of dedifferentiation. Mod Pathol 2005;18(7):976-84.
5. Fletcher CDM, Bridge JA, Hogendoorn PCW, et al. eds. World Health Organization classification of tumours of soft tissue and bone. $4^{\text {th }}$ edn. Lyon: IARC Press, 2013. 